\title{
Machine Learning Enabled Models to Predict Sulfur Solubility in Nuclear Waste
} Glasses

Xinyi $\mathrm{Xu}^{1}$, Taihao Han ${ }^{2}$, Jie Huang ${ }^{3}$, Albert A. Kruger, ${ }^{4}$ Aditya Kumar ${ }^{2 *}$, Ashutosh Goel $^{1 *}$

1. Department of Materials Science and Engineering, Rutgers, The State University of New Jersey, Piscataway, New Jersey, 08854, USA

2. Department of Materials Science and Engineering, Missouri University of Science and Technology, Rolla, MO, 65409, USA

3. Department of Electrical and Computer Engineering, Missouri University of Science and Technology, Rolla, MO, 65409, USA

4. U.S. Department of Energy, Office of River Protection, Richland, WA, 99354, USA

${ }^{*}$ Corresponding author

A. Goel, Email: ag1179@ soe.rutgers.edu; Ph: +1-848-445-4512

A. Kumar, Email: kumarad@ mst.edu; Ph: +1-573-341-6994 


\subsection{Overview of Machine Learning (ML) Models}

In this study, three machine learning models - Random Forests (RF), Support Vector Machine (SVM), and hybrid model - have been used to predict $\mathrm{SO}_{3}$ solubility in nuclear waste glasses. A brief description of each model is shown here, and the detail of each model can be found in our previous studies ${ }^{1-6}$. It is worth noting here that to achieve optimal prediction performance, hyperparameters and kernel functions (if applicable) of each model were optimized through 10-fold cross-validation $(\mathrm{CV})$ method $^{6-10}$ in conjunction with a grid-search method ${ }^{11}$.

\subsection{Support Vector Machine (SVM)}

Support vector machine (SVM), a commonly used ML model for both classification and regression purposes, approximates the correlation - either in the form of multivariate linear or nonlinear functions - between inputs and output of a dataset. This is accomplished by employing an optimization approach - as opposed to a regression approach - geared towards minimizing a $\operatorname{cost}\left(\varepsilon\right.$-insensitive loss) function ${ }^{12}$. During the training process, the model maps all input variables from a low-dimension to a high-dimension feature space through a mapping procedure. To undertake such mapping, a nonlinear kernel function (e.g., polynomial function, sigmoidal function, Gaussian radial basis kernel function, and hyperbolic tangent function ${ }^{13,14}$ ) is used. In this study, the Pearson VII function was used as the kernel function to map all input variables into higher dimensions. The optimum values of $\sigma$ and $\lambda$ were found as 0.5 and 0.5 based on the prediction performance. Due to its high-dimensional architecture, SVM model exhibits high accuracy and efficiency to process data with a large number of input variables. In our study, the database consists of more than 50 input attributes, in which the SVM model benefits from its intrinsic architecture. 


\section{Supporting Information}

\subsection{Random Forests (RF)}

Random Forests (RF) model - a modification of the classification-and-regression decision trees (CARTs) model - constructs a large number of uncorrelated, (CARTs) as a committee to produce independent outputs, and ultimately averages them produce the final output ${ }^{15}$. Each tree within the RF model is partitioned via binary splits into "near-homogeneous" terminal nodes; such partitioning is done in recursive fashion until optimal structure of the tree is achieved. RF leverages

the technique of bagging ${ }^{16,17}$, which ensures that each tree grows from a randomly-selected group of bootstrap samples, each comprising of the same number of inputs as the entire training dataset. $\mathrm{RF}$ also leverages another technique, bootstrapping, which helps reduce the variation (underfitting) and bias (overfitting) among the 100s-to-1000s of trees that are grown in the forest ${ }^{18}$. Another advantage of the RF model is that it allows each tree to grow to its maximum size without any smoothening or pruning whatsoever. This helps maintain diversity among the trees (i.e., output of each tree is truly independent of the output of all other trees), thereby allowing the model to not just capture trends in the dataset but also account for outliers. In this study, 500 trees and 9 splits at each node were set as the optimal hyper-parameters to produce predictions.

\subsection{Hybrid Model}

Hybrid model leverages two or more ML models and consolidates their predictions into a singular output that is more accurate than any prediction made by standalone ML models. In this study, the weighted voting ${ }^{19}$ method was used to combine the predictions from RF and SVM model and came up superior outputs. The contribution (measured in the form of vote) of each standalone ML model is ascertained based on its prediction accuracy (expressed in terms of $\mathrm{R}^{2}$ : coefficient of determination, or RMSE: root mean squared error) over the training dataset. More specifically, ML models with higher prediction accuracy are assigned superior weights than those 
with lower prediction accuracy (and, therefore, predictions made by the ML models with inferior prediction accuracy are not discarded). The final prediction is obtained by summing up all the votes - along with their weights - and selecting the ML model with superior aggregate vote compared to the others.

\subsection{Database Information}

Statistical parameters pertaining to the parent database used in this study are shown in Table S1. The parent database consisted of 1074 unique glass data-records, wherein each record had 51 inputs and 1 output. The inputs included pertinent physiochemical properties of the nuclear waste glasses: 47 normalized composition components (mass\%), melting temperature, melting time (hour), $\mathrm{SO}_{3}$ source $\left(1=\mathrm{NaSO}_{4}, 2=\right.$ other source $)$, and $\mathrm{SO}_{3}$ adding method $(1=$ saturation, 2 = gasbubbling). The output was the $\mathrm{SO}_{3}$ solubility in glasses (mass\%). Each glass composition has been normalized without $\mathrm{SO}_{3}$, while the $\mathrm{SO}_{3}$ concentration has been normalized relative to the total mass of the $\mathrm{SO}_{3}$-free glass.

Table S1: Summary of 4 statistical parameters pertaining to the 52 attributes (51 inputs and 1 output) of the $\mathrm{SO}_{3}$ solubility database for LAW and HLW glasses, consisting of 1074 unique datarecords. The output attribute is bold.

\begin{tabular}{|c|c|c|c|c|c|}
\hline Attribute & Unit & Min. & Max. & Mean & Std. Dev. \\
\hline $\mathrm{Al}_{2} \mathrm{O}_{3}$ Content & $\%_{\text {mass }}$ & 0 & 30.697 & 7.8903 & 3.4816 \\
$\mathrm{~B}_{2} \mathrm{O}_{3}$ Content & $\%_{\text {mass }}$ & 0 & 31.143 & 9.4058 & 3.5432 \\
$\mathrm{CaO}$ Content & $\%_{\text {mass }}$ & 0 & 20.294 & 5.0073 & 3.2725 \\
$\mathrm{Cl}$ Content & $\%_{\text {mass }}$ & 0 & 18.130 & 0.29488 & 0.61942 \\
$\mathrm{Cr}_{2} \mathrm{O}_{3}$ Content & $\%_{\text {mass }}$ & 0 & 15.035 & 0.23695 & 0.72709 \\
$\mathrm{Fe}_{2} \mathrm{O}_{3}$ Content & $\%_{\text {mass }}$ & 0 & 38.838 & 4.3652 & 5.7577 \\
$\mathrm{~K}_{2} \mathrm{O}$ Content & $\%_{\text {mass }}$ & 0 & 36.032 & 1.2972 & 2.5195 \\
$\mathrm{Li}_{2} \mathrm{O}$ Content & $\%_{\text {mass }}$ & 0 & 18.018 & 1.8034 & 2.1082 \\
$\mathrm{MgO}$ Content $^{\mathrm{Na}}$ & $\%_{\text {mass }}$ & 0 & 22.242 & 1.4809 & 1.5845 \\
$\mathrm{Na}_{2} \mathrm{O}$ Content & \%mass & 0 & 54.349 & 15.735 & 7.2230 \\
\hline
\end{tabular}


Supporting Information

\begin{tabular}{|c|c|c|c|c|c|}
\hline $\mathrm{P}_{2} \mathrm{O}_{5}$ Content & $\%_{\text {mass }}$ & 0 & 65.565 & 1.7576 & 8.2105 \\
\hline $\mathrm{SiO}_{2}$ Content & $\%_{\text {mass }}$ & 0 & 76.086 & 41.665 & 10.096 \\
\hline $\mathrm{SnO}_{2}$ Content & $\%_{\text {mass }}$ & 0 & 31.727 & 0.45752 & 1.3870 \\
\hline $\mathrm{TiO}_{2}$ Content & $\%_{\text {mass }}$ & 0 & 32.680 & 1.1921 & 3.9028 \\
\hline $\mathrm{V}_{2} \mathrm{O}_{5}$ Content & $\%_{\text {mass }}$ & 0 & 53.601 & 0.82236 & 2.5355 \\
\hline $\mathrm{ZnO}$ Content & $\%_{\text {mass }}$ & 0 & 5.9017 & 2.4597 & 1.5372 \\
\hline $\mathrm{ZrO}_{2}$ Content & $\%_{\text {mass }}$ & 0 & 9.0045 & 3.0211 & 1.9095 \\
\hline $\mathrm{BaO}$ Content & $\%_{\text {mass }}$ & 0 & 55.505 & 0.19215 & 2.6458 \\
\hline CdO Content & $\%_{\text {mass }}$ & 0 & 3.4758 & 0.02037 & 0.18308 \\
\hline $\mathrm{Cs}_{2} \mathrm{O}$ Content & $\%_{\text {mass }}$ & 0 & 11.579 & 0.09872 & 0.88696 \\
\hline F Content & $\%_{\text {mass }}$ & 0 & 3.0642 & 0.08331 & 0.16765 \\
\hline MnO Content & $\%_{\text {mass }}$ & 0 & 10.541 & 0.26746 & 0.90903 \\
\hline $\mathrm{NiO}$ Content & $\%_{\text {mass }}$ & 0 & 3.2758 & 0.08531 & 0.31831 \\
\hline PbO Content & $\%_{\text {mass }}$ & 0 & 41.300 & 0.12439 & 1.7768 \\
\hline $\operatorname{Re}_{2} \mathrm{O}_{7}$ Content & $\%_{\text {mass }}$ & 0 & 0.11350 & 0.00731 & 0.02405 \\
\hline SrO Content & $\%_{\text {mass }}$ & 0 & 10.074 & 0.06481 & 0.69442 \\
\hline $\mathrm{Tl}_{2} \mathrm{O}$ Content & $\%_{\text {mass }}$ & 0 & 0.28824 & 0.00127 & 0.01683 \\
\hline $\mathrm{ThO}_{2}$ Content & $\%_{\text {mass }}$ & 0 & 5.5895 & 0.01867 & 0.28108 \\
\hline $\mathrm{TeO}_{2}$ Content & $\%_{\text {mass }}$ & 0 & 0.00930 & 0.00003 & 0.00048 \\
\hline $\mathrm{SeO}_{2}$ Content & $\%_{\text {mass }}$ & 0 & 0.18596 & 0.00057 & 0.00962 \\
\hline $\mathrm{Sb}_{2} \mathrm{O}_{3}$ Content & $\%_{\text {mass }}$ & 0 & 0.50717 & 0.00057 & 0.01555 \\
\hline $\mathrm{RuO}_{2}$ Content & $\%_{\text {mass }}$ & 0 & 0.05298 & 0.00056 & 0.00494 \\
\hline $\mathrm{Rh}_{2} \mathrm{O}_{3}$ Content & $\%_{\text {mass }}$ & 0 & 0.05298 & 0.00048 & 0.00473 \\
\hline PdO Content & $\%_{\text {mass }}$ & 0 & 0.12716 & 0.00177 & 0.01401 \\
\hline $\mathrm{Nd}_{2} \mathrm{O}_{3}$ Content & $\%_{\text {mass }}$ & 0 & 13.333 & 0.01798 & 0.41368 \\
\hline $\mathrm{La}_{2} \mathrm{O}_{3}$ Content & $\%_{\text {mass }}$ & 0 & 2.0601 & 0.01781 & 0.11855 \\
\hline $\mathrm{CuO}$ Content & $\%_{\text {mass }}$ & 0 & 0.40468 & 0.00678 & 0.03023 \\
\hline $\mathrm{CoO}$ Content & $\%_{\text {mass }}$ & 0 & 0.21723 & 0.00154 & 0.01132 \\
\hline $\mathrm{Ce}_{2} \mathrm{O}_{3}$ Content & $\%_{\text {mass }}$ & 0 & 0.24850 & 0.00138 & 0.01546 \\
\hline $\mathrm{As}_{2} \mathrm{O}_{3}$ Content & $\%_{\text {mass }}$ & 0 & 2.0503 & 0.00339 & 0.06392 \\
\hline $\mathrm{Bi}_{2} \mathrm{O}_{3}$ Content & $\%_{\text {mass }}$ & 0 & 6.47636 & 0.04448 & 0.31689 \\
\hline $\mathrm{UO}_{3}$ Content & $\%_{\text {mass }}$ & 0 & 6.88778 & 0.04251 & 0.47394 \\
\hline $\mathrm{AgO}$ Content & $\%_{\text {mass }}$ & 0 & 0.17276 & 0.00095 & 0.00985 \\
\hline $\mathrm{MoO}_{3}$ Content & $\%_{\text {mass }}$ & 0 & 0.19678 & 0.00062 & 0.00750 \\
\hline $\mathrm{Y}_{2} \mathrm{O}_{3}$ Content & $\%_{\text {mass }}$ & 0 & 0.01623 & 0.00002 & 0.00049 \\
\hline $\mathrm{Gd}_{2} \mathrm{O}_{3}$ Content & $\%_{\text {mass }}$ & 0 & 0.05077 & 0.00050 & 0.00314 \\
\hline I Content & $\%_{\text {mass }}$ & 0 & 0.10166 & 0.00076 & 0.00827 \\
\hline $\begin{array}{c}\mathrm{SO}_{3} \text { Adding Method } \\
(1=\text { saturation, } 2=\text { bubbling })\end{array}$ & Unitless & 1 & 2 & 1.0270 & 0.16209 \\
\hline Melting Temperature & ${ }^{\circ} \mathrm{C}$ & 1100 & 1200 & 1155 & 15.554 \\
\hline Melting Time & Hour & 1 & 120 & 10.661 & 28.658 \\
\hline $\begin{array}{c}\mathrm{SO}_{3} \text { Source } \\
\left(1=\mathrm{Na}_{2} \mathrm{SO}_{4}, 2=\text { Other }\right)\end{array}$ & Unitless & 1 & 2 & 1.0707 & 0.25643 \\
\hline
\end{tabular}




\begin{tabular}{llllll}
$\mathrm{SO}_{3}$ Solubility & $\%$ mass & $\mathbf{0 . 0 2 2 9 8}$ & 4.76041 & 0.79410 & 0.43209 \\
\hline
\end{tabular}

\section{Reference}

(1) Han, T.; Khayat, K.; Ma, H.; Huang, J.; Kumar, A. Machine Learning for High-Fidelity Prediction and Optimization of Concrete Properties Poster, 2019.

(2) Han, T.; Khayat, K.; Ma, H.; Huang, J.; Kumar, A. Prediction of Compressive Strength and Modulus of Elasticity of Concrete Using Machine Learning Models. In Material Science \& Technology 2019; Oregon Convention Center, Portland, OR, 2019.

(3) Han, T.; Stone-Weiss, N.; Huang, J.; Goel, A.; Kumar, A. Machine Learning as a Tool to Design Glasses with Controlled Dissolution for Healthcare Applications. Acta Biomaterialia 2020, S1742706120301252. https://doi.org/10.1016/j.actbio.2020.02.037.

(4) Cook, R.; Lapeyre, J.; Ma, H.; Kumar, A. Prediction of Compressive Strength of Concrete: Critical Comparison of Performance of a Hybrid Machine Learning Model with Standalone Models. Journal of Materials in Civil Engineering 2019, 31 (11), 04019255. https://doi.org/10.1061/(ASCE)MT.1943-5533.0002902.

(5) Cai, R.; Yang, L. F.; Yu, B. Improved Model for Surface Chloride Concentration of Concrete in Marine Tidal and Splash Zones. Journal of Civil and Environmental Engineering 2019, 41, 122-129. https://doi.org/10.11835/j.issn.2096-6717.2019.079.

(6) Han, T.; Siddique, A.; Khayat, K.; Huang, J.; Kumar, A. An Ensemble Machine Learning Approach for Prediction and Optimization of Modulus of Elasticity of Recycled Aggregate Concrete. Construction and Building Materials 2020, 244, 118271. https://doi.org/10.1016/j.conbuildmat.2020.118271.

(7) Chou, J.-S.; Tsai, C.-F.; Pham, A.-D.; Lu, Y.-H. Machine Learning in Concrete Strength Simulations: Multi-Nation Data Analytics. Construction and Building Materials 2014, 73, 771-780. https://doi.org/10.1016/j.conbuildmat.2014.09.054.

(8) Han, T.; Stone-Weiss, N.; Huang, J.; Goel, A.; Kumar, A. Machine Learning as a Tool to Design Glasses with Controlled Dissolution for Application in Healthcare Industry. Acta Biomaterialia 2020, 107, 286-298. https://doi.org/10.1016/j.actbio.2020.02.037.

(9) Schaffer, C. Selecting a Classification Method by Cross-Validation. Machine Learning 1993, 13 (1), 135-143. https://doi.org/10.1007/BF00993106.

(10) Dietterich, T. G. Ensemble Methods in Machine Learning. In International workshop on multiple classifier systems; 2000; pp 1-15. https://doi.org/10.1007/3-540-45014-9_1.

(11) Eitrich, T.; Lang, B. Efficient Optimization of Support Vector Machine Learning Parameters for Unbalanced Datasets. Journal of Computational and Applied Mathematics 2006, 196 (2), 425-436. https://doi.org/10.1016/j.cam.2005.09.009.

(12) Smola, A. J.; Schölkopf, B. A Tutorial on Support Vector Regression. Statistics and computing 2004, 14 (3), 199-222.

(13) Clarke, S. M.; Griebsch, J. H.; Simpson, T. W. Analysis of Support Vector Regression for Approximation of Complex Engineering Analyses. J. Mech. Des 2004, 127 (6), 1077-1087. https://doi.org/10.1115/1.1897403.

(14) Garg, P.; Verma, J. In Silico Prediction of Blood Brain Barrier Permeability: An Artificial Neural Network Model. Journal of chemical information and modeling 2006, 46 (1), 289297. 
(15) Breiman, L. Bagging Predictors. Machine Learning 1996, 24 (2), 123-140. https://doi.org/10.1007/BF00058655.

(16) Breiman, L. Random Forests. Machine learning 2001, 45 (1), 5-32.

(17) Chen, X.; Ishwaran, H. Random Forests for Genomic Data Analysis. Genomics 2012, 99 (6), 323-329.

(18) Biau, Gãš.; Devroye, L.; Lugosi, Gãą. Consistency of Random Forests and Other Averaging Classifiers. Journal of Machine Learning Research 2008, 9 (Sep), 2015-2033.

(19) Polikar, R. Ensemble Learning. In Ensemble machine learning; Springer, 2012; pp 1-34. 